Article

\title{
The European Council, the Council, and the European Green Deal
}

\author{
Jeffrey Rosamond* and Claire Dupont \\ Department of Public Governance and Management, Ghent University, Belgium; \\ E-Mails: jeffrey.rosamond@ugent.be (J.R.), claire.dupont@ugent.be (C.D.) \\ * Corresponding author
}

Submitted: 30 March 2021 | Accepted: 15 August 2021 | Published: 30 September 2021

\begin{abstract}
We assess the response of the European Council and the Council of the European Union (hereafter the Council) to the emergence and development of the European Green Deal (EGD). First, we conduct a literature review of the historical role of the two intergovernmental institutions in EU climate policy development, drawing inspiration from new intergovernmentalism, historical institutionalism, and discursive institutionalism. Next, we provide an overview of the EGD itself and three of its core elements: (1) the ambition to achieve climate neutrality by 2050; (2) its systemic and integrative nature; and (3) the just transition approach. We then present the results of a qualitative content analysis of all Council and European Council Conclusions from 2018 to 2020. Our findings show that the European Council and the Council have declared support for the EGD and its underlying principles. The European Council engaged with all three elements but mentioned the objective of achieving net-zero emissions by 2050 most frequently and with growing intensity over the years studied. The Council similarly discussed the three elements of the EGD and gave increasing focus to the integrated/systemic transition over the course of the years 2018-2020. Our empirical analysis suggests that, on paper, the Council and the European Council may manage to govern through the organisational turbulence of member state divisions on climate governance. Furthermore, environmental turbulence arising from external contexts (e.g., economic and health crises) did not dampen their declared support towards the goals of the EGD.
\end{abstract}

\section{Keywords}

climate policy; Council of the European Union; European Council; European Green Deal; turbulence

Issue

This article is part of the issue "Climate Governance and the European Green Deal in Turbulent Times" edited by Claire Dupont (Ghent University, Belgium) and Diarmuid Torney (Dublin City University, Ireland).

(C) 2021 by the authors; licensee Cogitatio (Lisbon, Portugal). This article is licensed under a Creative Commons Attribution 4.0 International License (CC BY).

\section{Introduction}

The European Green Deal (EGD) was published by the European Commission (hereafter the Commission) in December 2019, fulfilling Ursula von der Leyen's promise to the European Parliament (hereafter the Parliament) before her confirmation as Commission President to place a Green Deal at the heart of her mandate. The EGD is an overarching policy framework designed to set the EU on the path towards climate neutrality by 2050 . It lays out the need for policies and strategies in overlapping systems, including food, industry, energy, buildings, mobility, and finance. The policy framework further sets out principles that guide the pursuit of the climate neutrality objective, including integrated action and a just transition in which no-one is left behind, coupled with diplomatic engagement to accelerate sustainability transitions globally (European Commission, 2019). On paper, the EGD seems to provide the sort of transformational response that the climate challenge requires (Bloomfield \& Steward, 2020; Dupont et al., 2020).

That Commission President von der Leyen pushed such an agenda, and that the Commission delivered the EGD early in her mandate, underlines previous scholarship emphasising the importance of both high-level political commitment to climate action and the Commission's 
entrepreneurial role (Dupont et al., 2020; Rietig \& Dupont, 2021). But policymaking in the EU is a complex endeavour involving multiple actors, including the Parliament and the Council of the European Union (hereafter the Council). Furthermore, outside of the legislative processes, the European Council provides strategic, political direction. We are interested in examining the official positions of the European Council and the Council concerning the emergence and development of the EGD to assess how the two intergovernmental actors responded to the policy framework. We analyse the institutions' responses as reported in their Conclusions, thereby providing indications of their approaches towards the EGD. The European Council and Council Conclusions are the product of intense, deliberative negotiations that occur within the intergovernmental bodies (Puetter, 2012 , 2014). They therefore represent the collective positions of the member state governments following discussions and compromises made at various levels, including in working groups, in the committees of Permanent Representatives (COREPER), and in the meetings of the Council and European Council. Furthermore, since the European Council does not provide minutes or recordings of its meetings, and the non-legislative functions of the Council are also held behind closed doors, the Conclusions are the only public source of negotiated member state positions (Hillebrandt \& Novak, 2016). While there are limits to focusing on the Conclusions as a source of data, our interest lies in understanding official stances and positions, making the documents a key data source. In this article, we build further on literature that draws (even partly) on the Conclusions to understand the Council's and European Council's approaches to the climate challenge (Dupont \& Oberthür, 2017; Skovgaard, 2014).

Research shows that the Council and European Council have previously weakened EU proposals for climate action, particularly owing to persistent internal disunity, which can be described as organisational turbulence (Dobbs et al., 2021; Dupont, 2016). This organisational turbulence has resulted in either incremental climate governance improvements (Kulovesi \& Oberthür, 2020), or else delayed climate action (Dobbs et al., 2021; Dupont \& Oberthür, 2017; Skovgaard, 2014). Divergences among the preferences of EU member states have previously blocked or delayed policy action during times of environmental turbulence, or turbulence in the external context, for example, after the financial and economic crises in the late 2000s (Burns et al., 2018; Dobbs et al., 2021; Skovgaard, 2014). At the onset of the Covid-19 crisis in 2020, expectations based on previous research that the EU, and particularly the Council and European Council, would lower ambition or stall climate policy development in response to a turbulent context have not (yet) been met (Burns \& Tobin, 2020; Dupont et al., 2020). Instead, the European Council adopted a recovery plan in 2020 that placed the EGD at its centre, perhaps indicating that the institution has adapted to governing with or through environmental and organisational turbulence towards the EGD (Dobbs et al., 2021). Our analysis sheds light on whether this is reflected in European Council and Council official positions.

The article proceeds as follows. First, we review literature on the contribution of the two intergovernmental institutions to EU climate policy development historically. We complement this review with insights from theoretical literature aiming to understand the functioning of the Council and European Council in EU integration in general, drawing on new intergovernmentalism (Bickerton et al., 2015; Fabbrini \& Puetter, 2016; Puetter, 2014) and institutionalist perspectives (Schmidt, 2008, 2010; Stark, 2018; Verdun, 2015). Second, we highlight three aspects of the EGD that could be seen as innovations in climate policy development, and that guide our empirical analysis. These are (1) the ambition to achieve climate neutrality by 2050; (2) the need for a systemic and integrative transition across sectors; and (3) the just transition approach (Bloomfield \& Steward, 2020; European Commission, 2019). Third, we present the results of our content analysis of 424 Council and European Council Conclusions from 2018 to 2020 . Our results reveal how often, in what context, and in what way the Council and European Council respond to the EGD and related climate governance issues. Fourth, we discuss our results with reference to previous literature on the Council and European Council in climate policy development in the EU, and to two types of turbulence as discussed by Dobbs, Gravey and Petetin (2021): organisational turbulence (internal divisions) and environmental turbulence (external contexts, like crisis events). We argue that official responses in both the European Council and Council have generally supported the ambition and multifaceted approach of the EGD. We conclude by outlining future research avenues and by highlighting the importance of further analysis as the EGD is implemented.

\section{The Council and the European Council in EU Climate Policy Development}

The European Council and the Council both bring representatives of member state governments together, but they serve different purposes. The Council is comprised of the ministers of the EU's member states. It acts as co-legislator (with the Parliament) on proposals initiated by the Commission under the EU's Ordinary Legislative Procedure. The European Council brings together the heads of state or government of the member states. It has no legislative role, but serves a political, agendasetting purpose, outlining the general priorities of the EU. These distinct roles are set out in the Treaty on European Union in Articles 15 and 16.

Broader scholarly research on the European Council and Council in European integration processes provides insights that may help in understanding intergovernmental responses to the EGD. First, new intergovernmentalist literature asserts that the European Council and 
Council tend to act beyond their roles and purposes as assigned under the Treaties (Bickerton et al., 2015; Fabbrini \& Puetter, 2016; Puetter, 2014). New intergovernmentalist scholars argue that the 1992 Maastricht Treaty led to an integration paradox in the EU: that the EU continues to deepen its integration and increase the domains over which it has competence without increasing degrees of supranationalism (Bickerton et al., 2015; Hodson \& Puetter, 2019; Puetter, 2014). These scholars therefore assert that member states recognise the importance of extending EU-level governance over contemporary policy challenges but are reluctant to surrender more power to the EU's supranationalist institutions, most notably, to the Commission (Bickerton et al., 2015; Hodson \& Puetter, 2019; Puetter, 2014). The European Council and the Council are understood as having become the "main catalysts" in driving integration and policymaking in new areas of EU competence, particularly in finance, justice and home affairs, and common foreign security and defence policy (CFSP/CSDP; Fabbrini \& Puetter, 2016, pp. 481-482), and that they have adopted a consensus-driven decision-making approach (Bickerton et al., 2015).

Second, different institutionalist perspectives of the European Council and the Council pay attention to the internal (sometimes turbulent) dynamics of the EU's intergovernmental institutions. Historical institutionalism suggests that institutions are largely stable, and that change occurs only incrementally following a logic of path dependency, unless swept off the path as the result of a critical juncture (Dupont et al., 2020; Stark, 2018; Verdun, 2015). Discursive institutionalism, however, underlines the role of ideas and discourse in explaining institutional change (Schmidt, 2008, p. 305). Foreground discursive abilities of agents allow them to communicate critically about institutions, which may result in persistence or change (Schmidt, 2008, 2010). Discourse can be both coordinative and communicative, with coordinative discourse involving the exchange of ideas among political actors, and communicative discourse referring to communication and projection of ideas to external audiences (Schmidt, 2008, 2010). Coordinative discourse is more likely to occur inside a complex political entity like the EU.

For our analysis of the Council's and the European Council's responses to the emergence and development of the EGD, new intergovernmentalism, historical institutionalism, and discursive institutionalism all provide helpful insights. From a new intergovernmentalist perspective, we would expect that the EGD progresses only with support from the intergovernmental institutions. Employing a historical institutionalist lens, we could expect the European Council and Council to continue along established institutional paths, thereby following previous trends of downgrading or deprioritising environmental and climate policy during times of crisis or environmental turbulence (Burns et al., 2018; Dobbs et al., 2021; Skovgaard, 2014). Finally, considering a discursive institutionalist perspective, explanations for European Council and Council responses to the EGD could stem from ideas communicated through discourses shared inside the EU institutions and to external audiences.

Previous research on the role of the European Council and Council in climate policy development shows underlying patterns of organisational turbulence (Dobbs et al., 2021). Organisational turbulence refers to turbulence within institutions, including conflict (Dobbs et al., 2021). In the context of the European Council and Council in climate policy governance, this internal, organisational turbulence can be most clearly identified in divergences among member states (Dupont et al., 2018; Skovgaard, 2014). Such organisational turbulence does not mean that governance is impossible, but it does require efforts to broker compromise and make decisions (Dobbs et al., 2021). Literature has shown that both the European Council and Council have been important players in the EU's climate policy development, but that at times, the internal, organisational turbulence delayed action or reduced ambition (Dupont, 2019; Wurzel, Liefferink, \& Di Lullo, 2019). Research has also shown that while certain external events, or environmental turbulence-like the financial crisis of the late 2000s-similarly led to delays and reduced ambition, other events have pushed the European Council and Council to advance on climate policy development (Dobbs et al., 2021). For example, annual negotiations on global climate governance under the United Nations Framework Convention on Climate Change (UNFCCC) provide regular pressure points for the EU to demonstrate global climate leadership, in line with its professed aims (Oberthür \& Dupont, 2021; Oberthür \& Roche Kelly, 2008; Wurzel, Liefferink, \& Di Lullo, 2019). Youth climate movements and Fridays for Future protests from 2018 also generated an environmental turbulent context that facilitated EU action (Dupont et al., 2020).

The heads of state and government in the European Council engaged with the climate challenge with increasing intensity over the years and pushed the EU to take a leading role globally in responding to climate change (Dupont, 2019; Oberthür \& Dupont, 2021; Wurzel, Liefferink, \& Torney, 2019). The European Council has, in the past, adopted the EU's climate policy targets in a consensus decision-making form (see, for example, European Council, 2007, 2014). But it has not limited itself to political steering and has also provided clear policy instructions, setting the scope for policy action in internal EU negotiations. In 2014, for example, it adopted the EU's goal to reduce greenhouse gas (GHG) emissions by $40 \%$ by 2030 , accompanied with detailed Conclusions on the shape of the policy instruments to achieve that goal (European Council, 2014). Ideas and discourses, such as the necessity of global leadership, the potential for ecological modernisation, and the security implications of climate impacts, have framed the European Council's historical political direction on climate governance (Dupont, 2019; Dupont \& Oberthür, 2017). 
The Council has a predominantly legislative function, but it also serves as a venue for political discussions to seek compromise among diverging political and policy preferences (Dupont \& Oberthür, 2017; Skovgaard, 2014). Finding compromise among coalitions of member states with incoherent priorities (e.g., promoting energy security through the use of fossil fuel sources versus promoting climate action through accelerated renewable energy roll-out) has at times been challenging, as demonstrated by Poland's refusal to align with the EU 2050 Energy Roadmap, published by the Commission in 2011 (European Commission, 2011; Skovgaard, 2014; Wurzel, Liefferink, \& Di Lullo, 2019). Coordination inside the multiple layers of the Council helps to achieve consensus that is more than the lowest-common denominator (Dupont, 2016). Although the $2008 / 2009$ economic and financial crises showed that it was challenging to maintain political interest in climate policy ambition during turbulent contexts (Burns et al., 2018; Skovgaard, 2014), "the interest in pursuing European strategies in response to common policy challenges has not declined. There is even further appetite for more intergovernmental policy coordination" (Puetter, 2012, p. 162). Ideas and discourses, such as securitisation and ecological modernisation, are also found in the Council's positions on climate policy development (Dupont, 2019; Dupont \& Oberthür, 2017).

\section{The Emergence and Development of the European Green Deal}

In many ways, the EGD may represent a break from previous incremental steps forward in EU climate governance (Dupont et al., 2020; Kulovesi \& Oberthür, 2020). It sets up a transformational framework that is novel for the EU via at least three main elements.

First, the overarching objective of achieving climate neutrality by 2050 is a step beyond previously envisioned policy ambition in the EU (i.e., a political goal of reducing emissions by $80-95 \%$ by 2050 , adopted by the European Council in 2009). The net-zero objective is a response to the aim of the Paris Agreement to keep global temperature increase below 2 degrees Celsius, and to strive to limit the increase to 1.5 degrees Celsius above preindustrial levels. More importantly, the EU's climate neutrality goal is embedded in the European Climate Law, making it legally-binding (Siddi, 2021).

Second, the transformational nature of the EGD is acknowledged through its systemic and integrative approach across sectors. The EGD states that "all EU actions and policies will have to contribute to the European Green Deal objectives" (European Commission, 2019, p. 3), and calls for legislative development across numerous domains, including headline topics: "mobilising industry for a clean and circular economy," "building and renovating in an energy and resource efficient way," "accelerating the shift to sustainable and smart mobility," and "From Farm to Fork: designing a fair, healthy, and environmentally-friendly food system." Scientific evidence underpinning such a systemic approach was growing in the years prior to the EGD's publication, for example, with the 2018 Intergovernmental Panel on Climate Change report on the impacts of 1.5 degrees Celsius of global warming (Masson-Delmotte et al., 2018). The Commission also presented a communication in 2018 calling for a climate neutrality goal by 2050, which laid the initial groundwork for the systemic and integrated approach advanced by the EGD (European Commission, 2018).

Third, the approach of the EGD moves the EU towards an economic strategy that emphasises a just transition in which no-one is left behind. According to the Commission, the EGD "aims to transform the EU into a fair and prosperous society, with a modern, resource-efficient and competitive economy where there are no net emissions of green-house gases in 2050 and where economic growth is decoupled from resource use" (European Commission, 2019, p. 2). The text highlights that "the transition must be just and inclusive. It must put people first, and pay attention to the regions, industries and workers who will face the greatest challenges" (European Commission, 2019, p. 2). The transition to climate neutrality should therefore be beneficial to all Europeans.

These three innovative aspects of the EGD-(legallybinding) ambition, its systemic and integrative nature, and a just transition approach-are of core interest in our analysis of the responses of the European Council and Council to the EGD in their Conclusions. We expect that the European Council and Council would approach the EGD in different ways, using different language, given their overarching roles and functions (see above).

\section{Analysing European Council and Council Responses to the European Green Deal}

We analysed all 424 Council and European Council Conclusions published between January 2018 and December 2020. We chose this time frame of analysis because we are interested in understanding the official positions of the two member state bodies immediately prior to and following the publication of the EGD. We analysed the Conclusions to highlight the institutions' positions on climate governance in general, and their stances on the emergence and development of the EGD. As the only public documentary evidence of discussions and deliberative consensus in the intergovernmental bodies, assessing the Conclusions is necessary to understand their agreed positions (Puetter, 2012, 2014). Therefore, the Conclusions are key sources of data for our approach. However, such an approach comes with limitations: The Conclusions are not legally binding, do not give us insight into the negotiating dynamics among the member states, and provide no evidence of individual member state interventions (Fabbrini \& Puetter, 2016; Hillebrandt \& Novak, 2016). We therefore discuss our results with these limitations in mind. 
In conducting our analysis, we first developed a codebook of key words or phrases, inspired by our review of literature on the European Council and Council in climate policy development. The codebook includes references that represent the variety of ways in which the intergovernmental bodies approached climate governance and (1) the goal of climate neutrality by 2050, (2) a systemic and integrative transformation or transition, and (3) a just transition. In Table 1 we provide an overview and categorisation of key terms in the codebook. The codebook was developed in an iterative manner: Terms were added as we noticed new ways in which the institutions commented on relevant issues, resulting in a compilation of 96 terms. The categorisation of the terms was similarly iterative. A first categorisation was developed and altered by both researchers separately. A combined categorisation was then checked via a close reading of the Conclusions, leading to further changes. For example, the key phrase "climate action" was categorised under the climate neutrality ambition category because coding here occurred when the institutions cited a general or specific call to action to meet the EU's climate neutrality goals. Similarly, the term "United Nations 2030 Agenda" was placed under the just transition category as coding occurred when the institutions placed the required transition prescribed by the EGD to tackle climate change within the broader context of sustainable development worldwide. We also included a list of "other" coded terms to catch references to policy instruments or related terms that did not readily fall under the other categories.

Second, we carried out a close reading of all the Conclusions analysed (see Table 2), to remove false hits and to achieve a deeper understanding of the results. For example, a statement like "Member states' ambition in achieving the objectives of the Paris Agreement" was recorded under "climate ambition," whereas a sentence such as "employment opportunities resulting from the green transition" was coded under "green jobs." Furthermore, some terms like the "United Nations SDGs,"

Table 1. Categorisation of terms in the codebook.

\begin{tabular}{ll}
\hline Coded terms \\
\hline Overarching terms & European Green Deal; climate change; climate challenge; climate emergency; climate \\
threat; climate security; climate protection; climate agenda; climate resiliency; climate \\
risk; (global/earth) warming; UNFCCC; Paris Agreement; Intergovernmental Panel on \\
Climate Change (IPCC); IPCC Special Report; Kyoto Protocol; greenhouse gas; GHG
\end{tabular}

Climate neutrality ambition

Climate action; climate targets; climate objectives; green objectives; climate ambition; climate neutrality; decarbonisation; net zero; temperature/climate goal; climate neutral economy; carbon neutrality; carbon neutral growth; low carbon; climate target plan; 2030 Climate Targets

Systemic and integrative nature of the EGD

Just transition

Other coded terms
Green recovery; (green/climate) transition; (green/climate) transformation; green architecture/infrastructure; climate neutral economy; carbon neutral growth; green/greening/greener sector/policy; green economy; sustainable economy; green jobs; climate/green investments; green/climate/low emissions technologies; green/sustainable growth; climate mainstreaming

United Nations Sustainable Development Goals (SDGs); United Nations 2030 Agenda; One Planet Summit; just/fair (transition/transformation); Just Transition Fund; Just Transition Scheme; Just Transition Mechanism

Climate interventions; climate practices; climate strategy; (natural) disaster; alternative fuel; carbon leakage; carbon market; carbon border adjustment mechanism; carbon storage; carbon accounting; carbon removal; fossil fuel; resource efficient; energy efficient; non-renewable; renewable; carbon/environmental footprint; carbon pricing; energy-intensive industries; clean energy/clean solutions; energy costs; climate policy; climate/green finance; climate requirements; climate sector; climate development; climate measures; climate co-benefits; adaptation; mitigation; Effort Sharing Regulation; Emissions Trading System (ETS); emissions; temperature increase; National Energy and Climate Plans; Low Emissions Development Strategy; Nationally Determined Contributions (NDCs); climate/green investments; green/climate/low emissions technologies; European Climate Law; climate and energy policy framework; climate and energy programmes; Low Emissions Development Strategy; green/climate innovation; circular economy/circularity; circular plastics economy; carbon-intensive sectors 
Table 2. Number of documents analysed per institution, per year.

\begin{tabular}{lcr}
\hline Year & European Council Conclusions & Council Conclusions \\
\hline 2018 & 8 & 127 \\
2019 & 9 & 154 \\
2020 & 4 & 122 \\
Total & 21 & 403 \\
\hline
\end{tabular}

which are mentioned in dozens of Conclusions, did not always pertain to climate policy or the EGD and were therefore not universally coded. Key words appearing in the title of a piece of legislation, policy, or proposal were not coded for further analysis.

\subsection{The European Council}

In the European Council, first, we observed that climate governance was a recurring issue in the Conclusions between 2018 and 2020. We analysed 21 European Council Conclusions, of which 11 (52.38\%) contained key words or phrases included in the codebook. Nine of the total number of European Council Conclusions focused solely on Brexit and one pertained only to the appointment of new senior EU officials. The remaining 12 European Council Conclusions mentioned multiple issues, with climate included in 11 of these (91.67\%). The Conclusions from the European Council meeting held on 28 June 2018 was the only multi-issue document that did not include any coded key term.

Second, we found that climate was the second most prominent issue mentioned in the European Council Conclusions. Of the 11 Conclusions that referenced climate or a coded term, eight $(72.73 \%)$ had an entire section devoted to climate issues. Only external relations/EU foreign policy concerns garnered greater attention (with a dedicated section in 10 Conclusions). Other prominent issues included security and defence (in six Conclusions), the Multi-Annual Financial Framework (five Conclusions), migration, social issues/European values, Covid-19, the Single Market, and Europe's Digital Strategy (each included in four Conclusions; see Table 3).
Third, we analysed the amount of space dedicated to climate governance and to the EGD in the Conclusions. We counted the number of paragraphs that included a coded term and measured that against the total number of paragraphs. Besides the official numbered paragraphs of the Conclusions, we also analysed paragraphs in the preamble and annex sections, if they were officially agreed by the institution. Bulleted lists were counted as one paragraph and preambles/annexes composed of several single or double lines of text were grouped together and counted as one paragraph. The 11 European Council Conclusions that referred to climate policy or a main element of the EGD had a total of 426 paragraphs, and $80(18.8 \%)$ included a coded term. But there are variations across the three years under examination. In 2018, coded terms appeared in $11.1 \%$ of paragraphs of three Conclusions of the European Council. Coded terms featured in one out of 16 (6.3\%) paragraphs in March 2018, in two out of 14 paragraphs (14.3\%) in October 2018 and in two out of 15 paragraphs (13.3\%) in December 2018. In 2019, 24.2\% of paragraphs of the four European Council Conclusions that mentioned climate governance contained a coded term. Coded terms featured in one out of nine paragraphs (11.1\%) in March 2019, 11 out of 58 paragraphs $(19 \%)$ in June 2019 , and one out of 12 paragraphs (8.3\%) in October 2019. The December 2019 European Council Conclusions-published on 12 December, the day after the Commission's publication of the EGDfeatured coded terms in 11 out of 20 paragraphs (55\%). In 2020, $18 \%$ of all paragraphs in the European Council Conclusions contained a coded term. Coded terms appeared in 26 out of 186 paragraphs (14\%) of the July

Table 3. Dedicated single-issue section headings in European Council Conclusions, 2018-2020.

\begin{tabular}{lc}
\hline Topic of Section & Total Number of Conclusions with the Section \\
\hline External Affairs/EU Foreign Policy Concern & 10 \\
Climate Change & 8 \\
Security and Defence & 6 \\
Multi-Annual Financial Framework & 5 \\
Single Market & 4 \\
Social Issues/European Values & 4 \\
Europe's Digital Transition & 4 \\
Covid-19 & 4 \\
Migration & 4 \\
Disinformation/Free Elections & 3 \\
Jobs, Competitiveness and Growth & 2 \\
\hline
\end{tabular}


2020 European Council Conclusions. These Conclusions laid out the Covid-19 recovery strategy. Coded terms were found in seven out of 30 paragraphs (23.3\%) and in five out of 24 (20.8\%) paragraphs of the two European Council Conclusions published in October 2020, and in 13 out of 24 paragraphs (40\%) in December 2020 (see Figure 1).

Fourth, we break the results down by category, to check if the European Council engaged with the three elements of the EGD as defined above. Of the 10 most frequently found coded terms, five are categorised under the climate neutrality goal group, one under the systemic and integrated nature of the EGD category, and one under the just transition category. Further, two of the most frequently found coded terms fall under the overarching terms category, and one was categorised under "other" climate governance terms. The most prominent terms found under the climate neutrality ambition category were: "climate objectives" (found 25 times in seven Conclusions), "climate action" (mentioned 22 times in eight different Conclusions), "climate neutrality" (cited 20 times in six different Conclusions), "climate target" (cited 20 times in three Conclusions), and "climate ambition" (coded 19 times in seven Conclusions). The terms "net zero," "carbon neutral growth," "climate neutral economy," and "climate target plan" were not found. Turning to the EGD's prescription for a systemic and integrated transition, the most frequently found term was "transition," which was cited 18 times in seven Conclusions. The other most frequent terms coded in this category included: "green/climate/low emissions technologies" (found six times in three Conclusions), "transformation" (cited five times in five Conclusions), "climate mainstreaming" (found four times in four Conclusions), and "green jobs" (cited three times in three different Conclusions). The terms "green architecture," "climate neutral economy," and "carbon neutral growth" were not found. Finally, under the just transition category, the term "just/fair (transition/transformation)" was found 12 times in six different Conclusions beginning in March 2019. Other terms coded under this category included: "Just Transition Mechanism" (found six times in three different Conclusions beginning in December 2019), "Just Transition Fund" (cited six times, only in the July 2020 Conclusions), and the "Just Transition Scheme" (referenced once in the July 2020 Conclusions). The European Council referred to the "United Nations Sustainable Development Goals" and its "2030 Agenda," as they pertain to integrating climate governance within a larger frame of inclusive and just global development goals, once each. The institution also mentioned overarching terms, including "climate change" (coded 22 times in nine Conclusions) and the "Paris Agreement" (coded 22 times in 11 Conclusions), and other general climate governance terms, such as "emissions," which was coded 10 times in five Conclusions. The term "European Green Deal" was found three times, in the December 2019 and July 2020 Conclusions.

\subsection{The Council}

We analysed 403 publicly available Council Conclusions, of which 127 were published in 2018, 154 in 2019, and 122 in 2020 (see Table 2). First, we found that 33 of the 127 Council Conclusions in 2018 (26\%), 54 of the 154 Council Conclusions in 2019 (35.1\%) and 64 of the 122 Council Conclusions in 2020 (52.5\%) contained a coded term (see Figure 2). Climate was the fifth most prominent issue mentioned in these Council Conclusions. Since most Council Conclusions deal with a single issue, we divided each of the Conclusions by policy field. If the Conclusions dealt with more than one topic equally, then all topics were recorded. We found external relations was most frequently discussed in the Council (118 Conclusions), followed by economics/finance (73 Conclusions), security/defence (56 Conclusions), the environment (30 Conclusions), and climate (25 Conclusions).

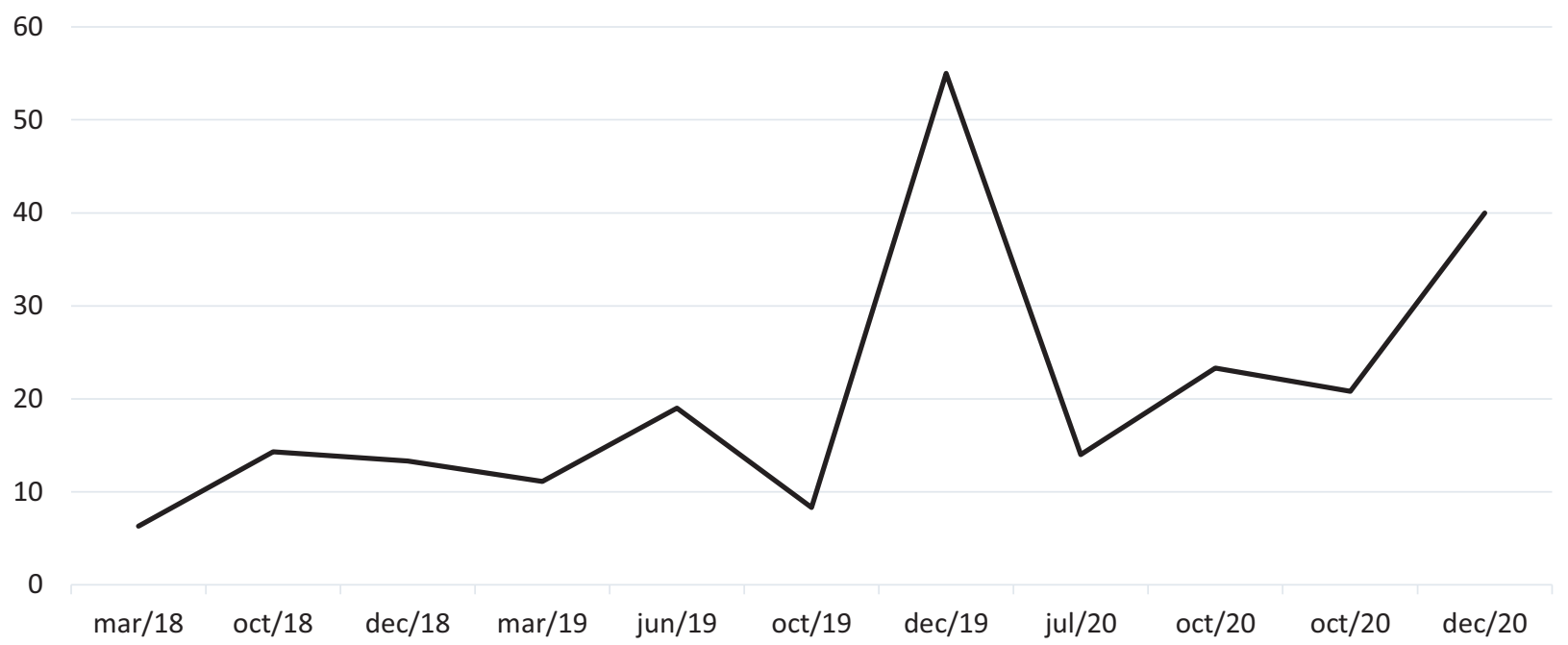

Figure 1. Percentage of total paragraphs in European Council Conclusions that contain a coded term. 


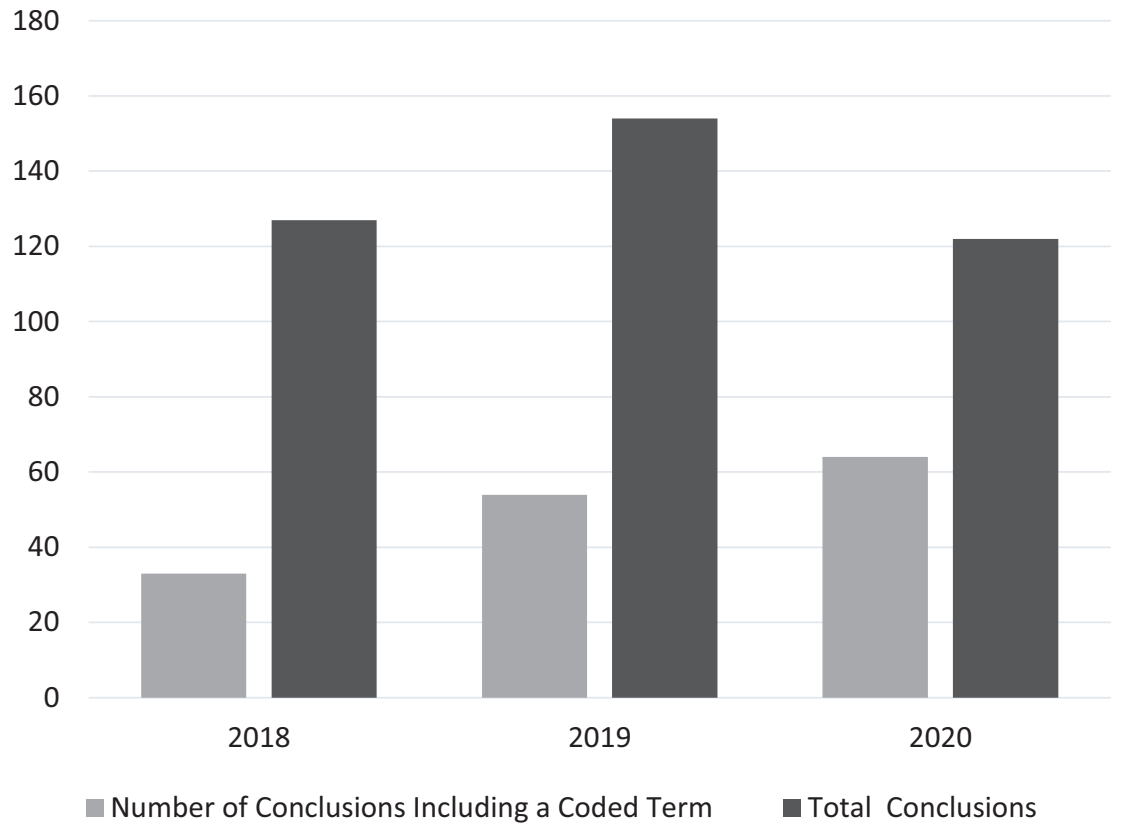

Figure 2. Conclusions including a coded term versus the total number of Council Conclusions published.

Second, we found coded terms in Conclusions with a central focus other than climate or the EGD. Results showed that 127 Conclusions that did not focus specifically on the EGD or climate issues contained a coded term. We coded terms in Conclusions focusing on external relations (55 Conclusions), economics/finance (24 Conclusions), and the environment (23 Conclusions), amongst other topics (see Table 4).

Third, the ratio of paragraphs including coded terms to total paragraphs in the Council Conclusions varied greatly over the three years. As noted above, while some Conclusions were devoted exclusively to EGD or climate policy matters, others mentioned coded terms embedded within another policy focus. In 2018 for example, paragraphs containing coded terms ranged from $1 \%$ to $100 \%$ of total paragraphs in a document. In total, $21.4 \%$ of all paragraphs contained a coded term in 2018.
In 2019 , we found that $24 \%$ of the total paragraphs in the Council Conclusions contained a coded term. In 2020, $20.3 \%$ of paragraphs contained a coded term.

Fourth, of the most frequently found coded terms in the Council Conclusions, four fall under the "other" climate governance terms category, three fall under the climate neutrality ambition category, two were classified under the overarching terms category and one belonged to the systemic/integrated transition category. Fewer coded terms were found under the just transition category. The most frequently cited coded terms classified within the ambition category included: "climate neutrality" (mentioned 137 times), "climate action" (found 90 times), and "climate ambition" (referenced 80 times). Other terms found in this category included "temperature/climate goal" (mentioned 44 times), "decarbonisation" (found 39 times), and "climate targets"

Table 4. Prominent topics of Conclusions and those that include coded terms.

\begin{tabular}{lcr}
\hline Topic Focus of the Conclusions & Total Number of Conclusions & Conclusions Containing a Coded Term \\
\hline External Relations & 118 & 55 \\
Economics/Finance & 73 & 24 \\
Security/Defence & 56 & 5 \\
Environment & 30 & 23 \\
Climate & 25 & $\mathrm{~N} / \mathrm{A}$ \\
Justice & 22 & 0 \\
Human Rights/European Values & 21 & 5 \\
Employment/Jobs & 19 & 10 \\
Women/Youth & 19 & 11 \\
Sport/Culture & 18 & 4 \\
Agriculture & 14 & 6 \\
Energy & 13 & 10 \\
Transportation & 12 & 6
\end{tabular}


(cited 25 times). The Council made reference to each coded term within the ambition category at least once. Under the integrated/systemic transition category, the term "transition" was found 196 times. Other terms coded frequently from this category included: "green/ climate/low- emissions technologies" (mentioned 54 times), "transformation" (cited 33 times), and "green/ greening/greener sector" (found 28 times). All other coded terms pertaining to the systemic transition prescribed by the EGD were also mentioned by the Council, but less frequently. Under the just transition category, the most cited terms included the "United Nations 2030 Agenda" (mentioned 65 times) and its "sustainable development goals" (found 73 times). The term "just/fair (transition/transformation)" was found 55 times (twice in 2018, 21 times in 2019, and 32 times in 2020). However, the terms "Just Transition Fund" and "Just Transition Scheme" were not found and the "Just Transition Mechanism" was mentioned twice in 2020. The Council also engaged with a wide variety of overarching terms, including "climate change" (coded 289 times), the "Paris Agreement" (found 197 times), and the "EGD" (coded 86 times), as well as "other" climate governance terms, including the "circular economy" (coded 246 times), and "renewable energy/sources" (cited 168 times). To see the full tally of coded terms per category, see Table 5 .

\subsection{Summary of Results}

In summary, we find that both the Council and the European Council responded to the emergence and development of the EGD in their Conclusions. In the European Council Conclusions, climate governance received its own heading more times than any other issue except for external relations and the issue was discussed in 11 out of 12 Conclusions focusing on multiple issues. In the case of the Council, Ministers referenced climate and EGD-related issues with increasing frequency across each year studied, including in negotiated positions on a wide range of policy topics ranging from agriculture to human rights. When it comes to the coded terms categorised under the three examined elements of the EGD, there are some trends and variations (see Table 5). Results from our analysis of the European Council Conclusions show that terms across all categories were cited more frequently with each suc- cessive year. For example, there were no key words or phrases coded under the just transition category in 2018, however we found 12 references in 2019 and 15 mentions in 2020. The greatest change was observed in the climate neutrality ambition category in which coded terms increased from six mentions in 2018 to 26 in 2019 to 84 in 2020 . The institution referenced terms pertaining to the climate neutrality objective more than terms associated with the overarching aspects of the EGD and the "other" climate governance terms category combined. In the Council, we similarly observed an increase across all categories of terms between 2018 and 2019. From 2019 to 2020, however, there was a decrease in mentions of coded terms in each category, except for the systemic/integrated transformation and "other" climate governance terms. The Council provided greater focus to the systemic/integrated transition with references increasing from 48 to 164 to 191 across successive years. However, as to be expected given its legislative role, the institution most frequently mentioned various policy instruments categorised within the "other" climate governance terms; here we see the number of coded references increase from 234 to 387 to 452 from 2018 to 2020.

\section{Discussion}

Previous scholarship on EU climate policy development, and the role of the Council and the European Council in this process, has highlighted several evolutions in the response of the member state institutions of the EU to the climate challenge (Dupont \& Oberthür, 2017; Skovgaard, 2014; Wurzel, Liefferink \& Di Lullo, 2019). First, the European Council and Council increasingly engaged with climate governance as the issue's political importance grew over time. Second, this engagement was characterised by organisational turbulence, stemming from internal policy divergences among member states and by environmental turbulence, arising from external contexts, such as economic crises. Our analysis of the European Council and Council Conclusions draws out their responses to the emergence and development of the EGD and provides some further nuance to the insights of previous literature.

Reflecting on the results of our empirical analysis, we first observe that it seems that not all periods of

Table 5. Coded terms found in the Conclusions, per year and per category.

\begin{tabular}{lrrrrrrr}
\hline & \multicolumn{3}{c}{ European Council } & & \multicolumn{3}{c}{ Council } \\
\cline { 2 - 3 } \cline { 5 - 7 } & 2018 & 2019 & 2020 & & 2018 & 2019 & 2020 \\
\hline Overarching Term & 11 & 26 & 28 & & 280 & 404 & 255 \\
Climate Neutrality Ambition & 6 & 36 & 84 & & 72 & 220 & 213 \\
Systemic/Integrated Transformation & 2 & 21 & 25 & & 48 & 164 & 191 \\
Just Transition & 0 & 12 & 15 & 44 & 79 & 78 \\
Other Climate Governance Term & 5 & 18 & 41 & & 234 & 387 & 452 \\
Total & 24 & 113 & 193 & 678 & 1254 & 1189 \\
\hline
\end{tabular}


environmental turbulence necessarily lead to member state reticence on EU climate governance. Given the history of climate and environmental policy development in the EU after the 2008/2009 crises, we could have expected a decline in engagement in the Council and European Council at the onset of the Covid-19 crisis from 2020 (Burns et al., 2018; Burns \& Tobin, 2020; Dobbs et al., 2021; Dupont et al., 2020). But our analysis shows that climate change and the EGD were mentioned in each of the European Council Conclusions published in 2020. Further, the July 2020 European Council Conclusions laid out the plan for the EU's recovery from the Covid-19 crisis and placed the EGD at the centre (European Council, 2020). Similarly, in the Council, the percentage of Council Conclusions mentioning a coded term related to climate or the EGD increased from $26 \%$ in 2018 to $35.1 \%$ in 2019 to $52.5 \%$ in 2020 . This finding provides evidence of increasing political focus given to the climate issue on paper by the Council and European Council over time. However, in this case, we see this increasing engagement also during an acute crisis, or turbulent environment.

Our results further indicate that the European Council and Council may manage to govern through or with organisational turbulence (Dobbs et al., 2021), with options pursued to ensure reticent member states find their place in a push for climate neutrality. Historically, organisational turbulence in the EU around climate policy development stemmed from internal member state divisions, particularly around the level and scope of climate policy ambition (Skovgaard, 2014). The just transition approach is part of a response to such divisions. Our analysis shows references in both the European Council and Council to climate neutrality throughout the years under analysis (2018-2020). In 2018, while the Council emphasised the importance of climate governance as a component of inclusive global development as per the UN SDGs, it refers to a just or fair transition only twice and this language is absent altogether in the 2018 European Council Conclusions. In 2019, we begin to see references to a just transition and its policy mechanisms in the Conclusions. The June 2019 European Council Conclusions, for example, state that the transformation of the EU's society and economy to achieve climate neutrality must be undertaken "in a way that takes account of national circumstances and is socially just" (European Council, 2019, p. 9). The just transition became embedded in the EGD when published in December 2019, allowing the more reticent member states (e.g., Poland) to agree to the overall ambition. In this case, the historical, organisational turbulence did not prevent member states from moving forward on the EGD and climate governance, which demonstrates some capacity to govern despite institutional divisions.

Finally, our exploratory analysis also links to some insights from new intergovernmentalism and historical and discursive institutionalism. We have demonstrated that climate governance and the EGD are men- tioned regularly in the Council and the European Council Conclusions. This provides some initial backing to the new intergovernmentalist idea that the intergovernmental institutions of the EU (and especially the European Council) extend their functioning beyond their Treaty roles in areas of shared competence (Fabbrini \& Puetter, 2016; Skovgaard, 2014). However, further research conducted during subsequent phases of policy development is needed to explore this phenomenon. Through a historical institutionalist lens, we could lend some initial support to scholarship exploring the notion that the EGD itself represents a critical juncture in EU climate policymaking (Dupont et al., 2020). Prior to the emergence of the EGD, the Council and European Council supported incremental increases in climate policy ambition (Kulovesi \& Oberthür, 2020). But our analysis shows that both institutions discussed the climate neutrality goal in the lead up to the publication of the EGD and found a way to govern despite member state divisions. The declared level of ambition was not diluted or derailed as a result of the Covid-19 crisis (Dupont et al., 2020). Finally, drawing on insights from discursive institutionalism, we could identify and analyse responses to three main elements of the EGD in the European Council and the Council Conclusions. Discursive institutionalism highlights the importance of the role of ideas in facilitating institutional change and our analysis may indicate that by focusing on the ideas of climate neutrality in the European Council, of an integrated/systemic transformation in the Council, and of the just transition approach in both institutions, organisational turbulence or resistance to climate ambition could be overcome.

\section{Conclusions}

Through its Conclusions, the intergovernmental arm of the EU has responded to the EGD and its three underlying principles: the ambition to achieve climate neutrality by 2050 , an integrated and systemic transformation, and a just and inclusive transition. While the Commission proposed raising the level of EU climate ambition and set out these elements with the EGD, the European Council and Council provided negotiated member state positions supporting these moves.

Over the course of the three years studied, we found increasing recognition of the need for society-wide transition and/or transformation in the realm of climate governance in the institutions' Conclusions, even during the height of the Covid-19 crisis in 2020. While studying the Conclusions is important to understand the common, negotiated positions of the Council and the European Council, an important limitation to such an approach is that it does not provide insights into individual member state stances. Research revealing these member state positions would be welcome for further nuance and would require other approaches. Although the environmental and organisational turbulence seem to have been overcome, or at least did not prevent agreement on the 
climate ambition in the European Council and Council during the emergence and development of the EGD, these sources of turbulence may disrupt the legislative process as the member states negotiate concrete policy options alongside the Parliament. Further research on strategies for maintaining political focus during periods and situations when organisational turbulence comes to the fore is also necessary, both for understanding the functioning of the European Council and Council in climate governance, and for mitigating and preparing for future challenges to achieving the goal of a climate neutral Europe.

\section{Acknowledgments}

This article was prepared in the context of the Jean Monnet Network "Governing the EU's climate and energy transition in turbulent times" (GOVTRAN: www.govtran.eu), with the support of the Erasmus+ programme of the European Union. We would like to thank the other thematic issue contributors, the participants at the ECPR Joint Sessions in 2020 and four anonymous reviewers for their helpful comments on earlier drafts of this article. We would also like to thank the Thematic Issue and journal editors for their patient guidance and support.

\section{Conflict of Interests}

The authors declare no conflict of interests.

\section{References}

Bickerton, C. J., Hodson, D., \& Puetter, U. (2015). The new intergovernmentalism: European integration in the post-Maastricht era. Journal of Common Market Studies, 53(4), 703-722.

Bloomfield, J., \& Steward, F. (2020). The politics of the Green New Deal. The Political Quarterly, 91(4), 770-779.

Burns, C., \& Tobin, P. (2020). Crisis, climate change and comitology: Policy dismantling via the backdoor? JCMS: Journal of Common Market Studies, 58(3), 527-544.

Burns, C., Tobin, P., \& Sewerin, S. (2018). The impact of the economic crisis on European environmental policy. Oxford University Press.

Dobbs, M., Gravey, V., \& Petetin, L. (2021). Driving the European Green Deal in turbulent times. Politics and Governance, 9(3), 316-326.

Dupont, C. (2016). Climate policy integration into EU energy policy: Progress and prospects. Routledge.

Dupont, C. (2019). The EU's collective securitisation of climate change. West European Politics, 42(2), 369-390.

Dupont, C., \& Oberthür, S. (2017). The Council and the European Council: Stuck on the road to transformational leadership. In R. K. W. Wurzel, J. Connelly, \&
D. Liefferink (Eds.), The European Union in international climate change politics: Still taking a lead? (pp. 66-79). Routledge.

Dupont, C., Oberthür, S., \& Biedenkopf, K. (2018). Climate change: Adapting to evolving internal and external dynamics. In C. Adelle, K. Biedenkopf \& D. Torney (Eds.), European Union external environmental policy: Rules, regulations, and governance beyond borders (pp. 105-124). Palgrave Macmillan.

Dupont, C., Oberthür, S., \& von Homeyer, I. (2020). The Covid-19 crisis: A critical juncture for EU climate policy development? Journal of European Integration, 42(8), 1095-1110.

European Commission. (2011). Energy Roadmap 2050 (COM (2011) 885).

European Commission. (2018). A clean planet for all (COM (2018) 773).

European Commission. (2019). The European Green Deal (COM (2019) 640).

European Council. (2007). Conclusions, March (7224/07).

European Council. (2014). Conclusions, October (EUCO 169/14).

European Council. (2019). Conclusions, June (EUCO 9/19).

European Council. (2020). Conclusions, July (EUCO 10/20).

Fabbrini, S., \& Puetter, U. (2016). Integration without supranationalisation: Studying the lead roles of the European Council and the Council in post-Lisbon EU politics. Journal of European Integration, 38(5), 481-495.

Hillebrandt, M., \& Novak, S. (2016). 'Integration without transparency'? Reliance on the space to think in the European Council and Council. Journal of European Integration, 38(5), 527-540.

Hodson, D., \& Puetter, U. (2019). The European Union in disequilibrium: New intergovernmentalism, postfunctionalism and integration theory in the postMaastricht period. Journal of European Public Policy, 26(8), 1153-1171.

Kulovesi, K., \& Oberthür, S. (2020). Assessing the EU's 2030 climate and energy policy framework: Incremental change toward radical transformation? Review of European, Comparative \& International Environmental Law, 29(2), 151-166.

Masson-Delmotte, V., Zhai, P., Pörtner, H.-O., Roberts, D., Skea, J., Shukla, P. R., Pirani, A., Moufouma-Okia, W., Péan, C., Pidcock, R., Connors, S., Matthews, J. B. R., Chen, Y., Zhou, X., Gomis, M. I., Lonnoy, E., Maycock, T., Tignor, M., \& Waterfield, T. (Eds.). (2018). Global warming of $1.5^{\circ} \mathrm{C}$. Intergovernmental Panel on Climate Change.

Oberthür, S., \& Dupont, C. (2021). The European Union's international climate leadership: Towards a grand climate strategy. Journal of European Public Policy, 28(7), 1095-1114.

Oberthür, S., \& Roche Kelly, C. (2008). EU leadership in 
international climate policy: Achievements and challenges. The International Spectator, 43(3), 35-50.

Puetter, U. (2012). Europe's deliberative intergovernmentalism: The role of the Council and European Council in EU economic governance. Journal of European Public Policy, 19(2), 161-178.

Puetter, U. (2014). The European Council and the Council: New intergovernmentalism and institutional change. Oxford University Press.

Rietig, K., \& Dupont, C. (2021). Presidential leadership styles and institional capacity for climate policy integration in the European Commission. Policy and Society, 40(1), 19-36.

Schmidt, V. A. (2008). Discursive institutionalism: The explanatory power of ideas and discourse. Annual Review of Political Science, 11, 303-326.

Schmidt, V. A. (2010). Taking ideas and discourse seriously: Explaining change through discursive institutionalism as the fourth 'new institutionalism.' European Political Science Review, 2(1), 1-25.
Siddi, M. (2021). Coping with turbulence: EU negotiations on the 2030 and 2050 climate targets. Politics and Governance, 9(3), 327-336.

Skovgaard, J. (2014). EU climate policy after the crisis. Environmental Politics, 23(1), 1-17.

Stark, A. (2018). New institutionalism, critical juncture, and post-crisis policy reform. Australian Journal of Political Science, 53(1), 24-30.

Verdun, A. (2015). A historical institutionalist explanation of the EU's responses to the euro area financial crisis. Journal of European Public Policy, 22(2), 24-39.

Wurzel, R. K. W., Liefferink, D., \& Di Lullo, M. (2019). The European Council, the Council and the member states: Changing environmental leadership dynamics in the European Union. Environmental Politics, 28(2), 248-270.

Wurzel, R. K. W., Liefferink, D., \& Torney, D. (2019). Pioneers, leaders and followers in multilevel and polycentric climate governance. Environmental Politics, 28(1), 1-21.

\section{About the Authors}

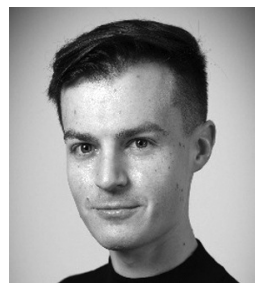

Jeffrey Rosamond is a doctoral researcher in the European and International Governance Research Group at the Department of Public Governance and Management, Ghent University, Belgium. His research focuses on climate policymaking in the European Union.

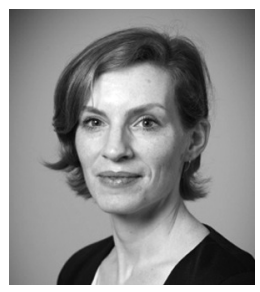

Claire Dupont is assistant professor of European Governance at the Department of Public Governance and Management, Ghent University, Belgium. She has published research on EU climate and energy policy in books and various journals, including Journal of European Public Policy, West European Politics and Journal of European Integration. She is a management board member of the Jean Monnet Network "Governing the EU's climate and energy transition in turbulent times" (GOVTRAN). 